\title{
Physiological and morphological determinants of maximal expirato- ry flow in chronic obstructive lung disease
}

\author{
H.A.W.M. Tiddens*, J.M. Bogaard**, J.C. de Jongste*, W.C.J. Hop ${ }^{+}$, \\ H.O. Coxson ++ , P.D. Paré ++
}

Physiological and morphological determinants of maximal expiratory flow in chronic obstructive lung disease. H.A.W.M. Tiddens, J.M. Bogaard, J.C. de Jongste, W.C.J. Hop, H.O. Coxson, P.D. Paré. (CERS Journals Ltd 1996.

ABSTRACT: Maximal expiratory flow in chronic obstructive pulmonary disease (COPD) could be reduced by three different mechanisms; loss of lung elastic recoil, decreased airway conductance upstream of flow-limiting segments; and increased collapsibility of airways.

We hypothesized that decreased upstream conductance would be related to inflammation and thickening of the airway walls, increased collapsibility would be related to decreased airway cartilage volume, and decreased collapsibility to inflammation and thickening of the airway walls.

Lung tissue was obtained from 72 patients with different degrees of COPD, who were operated upon for a solitary peripheral lung lesion. Maximal flow-static recoil (MFSR) plots to estimate upstream resistance and airway collapsibility were derived in 59 patients from preoperatively measured maximal expiratory flow-volume and pressure-volume curves. In 341 transversely cut airway sections, airway size, airway wall dimensions and inflammatory changes were measured.

Airflow obstruction correlated with lung elastic recoil and the MFSR estimate of airway conductance but not to airway collapsibility or to the amount of airway cartilage. The upstream conductance decreased as the inner wall became thicker. Airway collapsibility did not correlate with the amount of airway cartilage, inflammation, or airway wall thickness. We conclude that the maximal flow-static recoil model does not adequately reflect the collapsibility of the flow-limiting segment.

Eur Respir J., 1996, 9, 1785-1794.
*Dept of Pediatrics, Division of Respiratory Medicine, **Lung Function Laboratory and +Dept of Biostatistics, Erasmus University and University Hospital/Sophia Children's Hospital, Rotterdam, The Netherlands. +'Respiratory Health Network of Centres of Excellence, St. Paul's Hospital Pulmonary Research Laboratory, University of British Columbia, Vancouver, Canada.

Correspondence: H.A.W.M. Tiddens Sophia Children's Hospital

Dr Molewaterplein 60

3015 GJ Rotterdam

The Netherlands

Keywords: Airflow obstruction airway inflammation

bronchial hyperresponsiveness cartilaginous airways

chronic obstructive pulmonary disease maximal flow-static recoil

Received: October 301995

Accepted after revision May 241996
Reduced maximal expiratory flow is the physiological abnormality which defines chronic obstructive pulmonary disease (COPD) and is used as a measure of its severity. Nevertheless, the exact mechanisms which are responsible for the airflow obstruction in COPD remain incompletely understood. Maximal expiratory flow in COPD could be reduced by three different mechanisms. Firstly, loss of lung elastic recoil can decrease the driving pressure $[1,2]$. Secondly, inflammatory thickening and narrowing of airways can decrease the airway conductance upstream of flow-limiting segments. Thirdly, the collapsibility of airways and, therefore, of flow-limiting segments can be increased due to processes such as inflammatory destruction of bronchial cartilage. Decreased cartilage volume in COPD has been described by several authors [3-6], but was not found by others [7, 8].

It has been suggested that the relative contributions of decreased lung recoil, decreased airway conductance and increased airway collapsibility to flow obstruction during forced expiration can be estimated from a maximal flow-static recoil (MFSR) curve [9]. MFSR curves can be constructed by plotting maximal flow at specific lung volumes versus the corresponding transpulmonary pressures. These measures are derived from maximal expiratory flow-volume and pressure-volume curves. The slope of the MFSR plot is a measure of airway conductance upstream from the flow-limiting segments. The pressure-axis intercept of the MFSR curve is an index of the collapsibility of the flow-limiting segments.

We hypothesized that decreased upstream conductance would be related to inflammation and thickening of the airway walls, increased collapsibility would be related to decreased airway cartilage volume, and decreased collapsibility to inflammation and thickening of the airway walls.

These questions were addressed by measuring maximal expiratory flow-volume and pressure-volume curves and constructing MFSR plots for 72 patients who had varying degrees of airflow obstruction. Lung function measurements were made in the week before resection of a lung or lobe for a peripheral pulmonary lesion. With these in vivo parameters of lung elastic recoil, MFSR estimates of airway conductance and collapsibility together with morphometric measurements of the airway structure, an attempt was made to separate the relative importance of decreased recoil, decreased upstream conductance and increased collapsibility of the flow-limiting segments to airflow obstruction in COPD. 
Table 1. - Study population characteristics $(n=72)$

\begin{tabular}{lc}
\hline Age yrs & $61 \pm 9.5$ \\
& $(37-83)$ \\
Sex M/F & $54 / 18$ \\
Pack-yrs ${ }^{\dagger}$ & $54.7 \pm 34.5$ \\
& $(0.4-180)$ \\
Current smokers n & 45 \\
Lifelong nonsmokers n & 2 \\
Lung or lobe resected, right side n & 50 \\
Lung or lobe resected, left side n & 22
\end{tabular}

$t$ : pack-yrs=numbers of years smoking one pack of cigarettes a day. Age and pack years are expressed as mean \pm SD and range in parenthesis. M: male; F: female.

\section{Methods}

\section{Study population}

Lung tissue was obtained from 72 patients who had a lobar resection or pneumonectomy for a solitary peripheral lung lesion, and who showed no evidence at pathological examination of obstructive pneumonitis. Furthermore, patients who had a history consistent with a diagnosis of asthma were excluded [10]. Informed consent was obtained in all cases. Of the 72 patients, 64 proved to have bronchogenic carcinoma; carcinoid tumour, hamartoma or granuloma was the final diagnosis in the remaining patients. The clinical data for patients in this study are summarized in table 1 .

\section{Pulmonary function studies}

Pulmonary function tests were performed in the week before surgery using a volume displacement pressure compensated body plethysmograph. Thoracic gas volume was measured with a Krogh spirometer coupled to a linear displacement transducer (Shaevitz Engineering, Pennsauken, NJ, USA). Flow was measured with a Fleisch No. 3 pneumotachometer coupled to a Sanborn 270 differential pressure transducer (Sanborn Co., Waltham, MA, USA). Functional residual capacity (FRC) was determined using the Boyle's law technique, and residual volume (RV) and total lung capacity (TLC) were calculated after the determination of the expiratory reserve volume and inspiratory capacity (IC). Forced expiratory volume in one second (FEV1) and forced vital capacity (FVC) were calculated from digitized flow and volume signals obtained during forced expiratory manoeuvres. At least three expiratory efforts were performed and the forced expiratory manoeuvre with the largest sum of FEV1 and FVC was selected. As an indicator of the severity of flow obstruction, the FEV1 and FEV1/FVC were used. Values were expressed as percentage of the predicted values (\% pred) according to the summary equations of the European Coal and Steel Community [11].

Static pressure-volume curves were obtained as described previously [12]. Briefly, transpulmonary pressure $(P \mathrm{~L})$ was measured using a differential pressure transducer (Validyne 45MP $\pm 100 \mathrm{cmH}_{2} \mathrm{O}$; Validyne Co., Northridge, CA, USA), which compared airway opening pressure to oesophageal pressure measured with a bal- loon catheter. The volume signal was obtained from the body plethysmograph. After three vital capacity breaths, the subjects inhaled to TLC and the maximal static recoil pressure $(P \mathrm{~L}, \max )$ was recorded with the glottis opened. Multiple static pressure-volume points were obtained by occluding the airway every $1-2 \mathrm{~s}$ during slow expiration to FRC. At least three curves were obtained and a total of not less than 18 pressure-volume points. The pressure-volume data were analysed as described previously $[13,14]$. All pressure-volume points between TLC and FRC were used to derive an exponential relationship of the form: $V=\mathrm{A}-\mathrm{Be}^{-\mathrm{k} P}$, where: $V=$ lung volume; $\mathrm{A}=$ the lung volume at infinite $P \mathrm{~L} ; \mathrm{B}=$ the lung volume difference between $\mathrm{A}$ and the lung volume at a $P \mathrm{~L}$ of 0 ; $\mathrm{k}=$ the exponential constant that describes the shape of the pressure-volume curve; and $P=$ transpulmonary pressure. The recoil pressures at 90 and $60 \%$ TLC ( $P$ L,90 and $P \mathrm{~L}, 60)$ were calculated, using the $V=\mathrm{A}-\mathrm{Be}^{-\mathrm{k} P}$ equation $[13,14]$.

\section{Construction of maximal flow-static recoil curves}

A MFSR curve was obtained for each patient by plotting maximal expiratory flow against the static transpulmonary pressures at the same lung volumes (fig. 1). The slope of the relatively linear part of the MFSR plot between 70 and 30\% vital capacity (VC) was calculated to estimate upstream airway conductance during forced expiration ( $G$ us: $\mathrm{L}^{-} \mathrm{s}^{-1} \cdot \mathrm{cmH}_{2} \mathrm{O}^{-1}$ ). For comparison with previous reports on MFSR analysis, $G$ us was also divided by TLC (sGus: $\mathrm{cmH}_{2} \mathrm{O} \cdot \mathrm{s}^{-1}$ ). The pressure-axis intercept of the extrapolated slope was used to estimate the critical transmural pressure causing airway collapse at the flow limiting segment $\left(P \mathrm{tm}\right.$ ': $\left.\mathrm{cmH}_{2} \mathrm{O}\right)$ at which flowlimiting airways narrow sufficiently to restrict airflow according to the model described by PRIDE et al. [15].

Predicted $G$ us and $P \mathrm{tm}^{\prime}$ ( $G$ us(pred) and $P \mathrm{tm}^{\prime}($ pred)) were predicted for individual patients as follows (fig. 1). Firstly, TLC and FVC(pred) were calculated using the equations of QuANJER et al. [11]. Secondly, the absolute lung volumes at 75, 50 and $25 \%$ FVC (pred) were calculated by subtracting, respectively, 25,50 or $75 \%$ of FVC(pred) from TLC(pred). Thirdly, the predicted recoil pressures for these three lung volumes were calculated as follows: the $V=\mathrm{A}-\mathrm{Be}^{-\mathrm{k} P}$ equation was rearranged to $P=((\ln \mathrm{A}-V)-$ $\ln \mathrm{B}) / \mathrm{k}$, where $V$ is the lung volume at 75,50 and $25 \%$ $\mathrm{FVC}$ (pred) and $\mathrm{A}$ is the theoretical lung volume at infinite transpulmonary pressure (we used TLC(pred) for A). $\mathrm{K}$ and $\mathrm{B}$ were derived from the prediction equations of Colebatch et al. [14] for $\mathrm{k}$ and B/A\%. Fourthly, the maximal expiratory flows at 75, 50 and $25 \% \mathrm{FVC}$ (pred) were derived from the equations of QuANJER et al. [11]. The three predicted flow recoil-pressure points at 75, 50 and $25 \%$ FVC(pred) were plotted on a flow-pressure diagram and a regression line was plotted through the three flow-pressure points for the $75-25 \%$ VC volume intervals. The slope of the regression equation represents Gus(pred) and the intercept on the pressure-axis represents $P$ tm'(pred). For statistical analysis, $G$ us was expressed as a percentage of $G$ us(pred) $(G$ us $\%)$ and $P \mathrm{tm}^{\prime}$ as the absolute difference of $P \mathrm{tm}^{\prime}\left(\right.$ pred) - $P \mathrm{tm}^{\prime}\left(\Delta P_{\mathrm{tm}}{ }^{\prime}\right)$ (fig. 1). With increased collapsibility of the flow-limiting segment, $P \mathrm{tm}^{\prime}$ will be more positive and, therefore, $\Delta P \mathrm{tm}^{\prime}$ more negative. 
Predicted
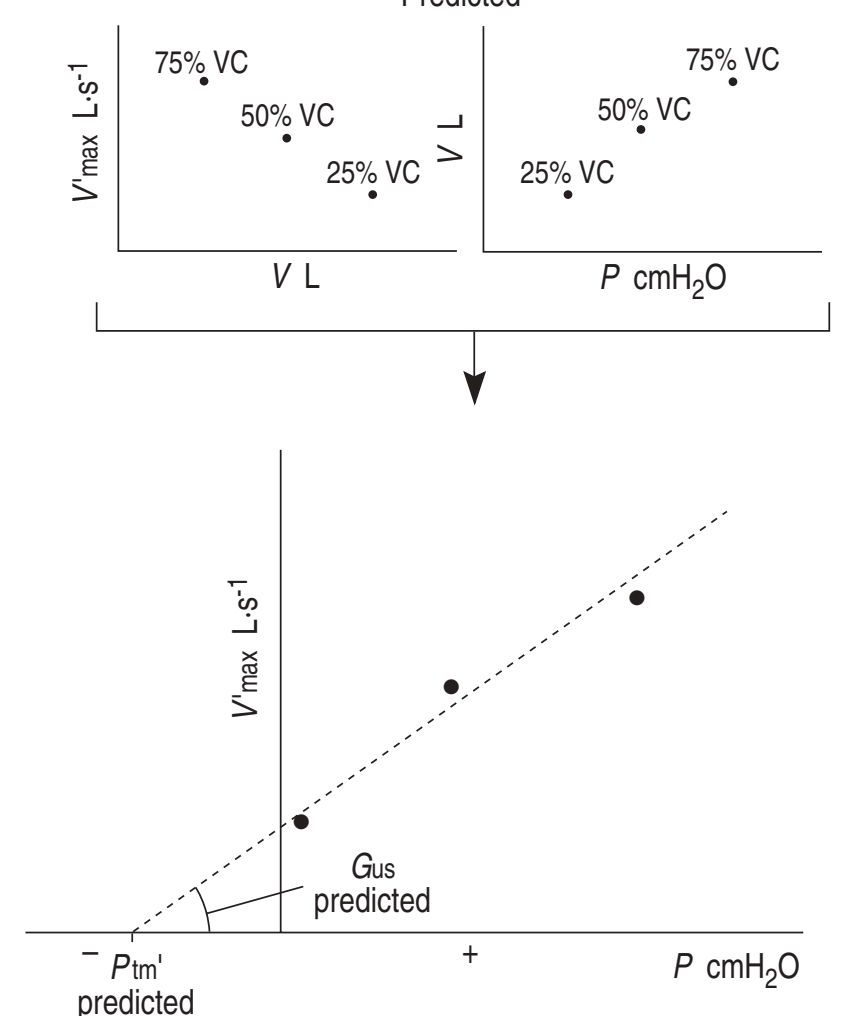
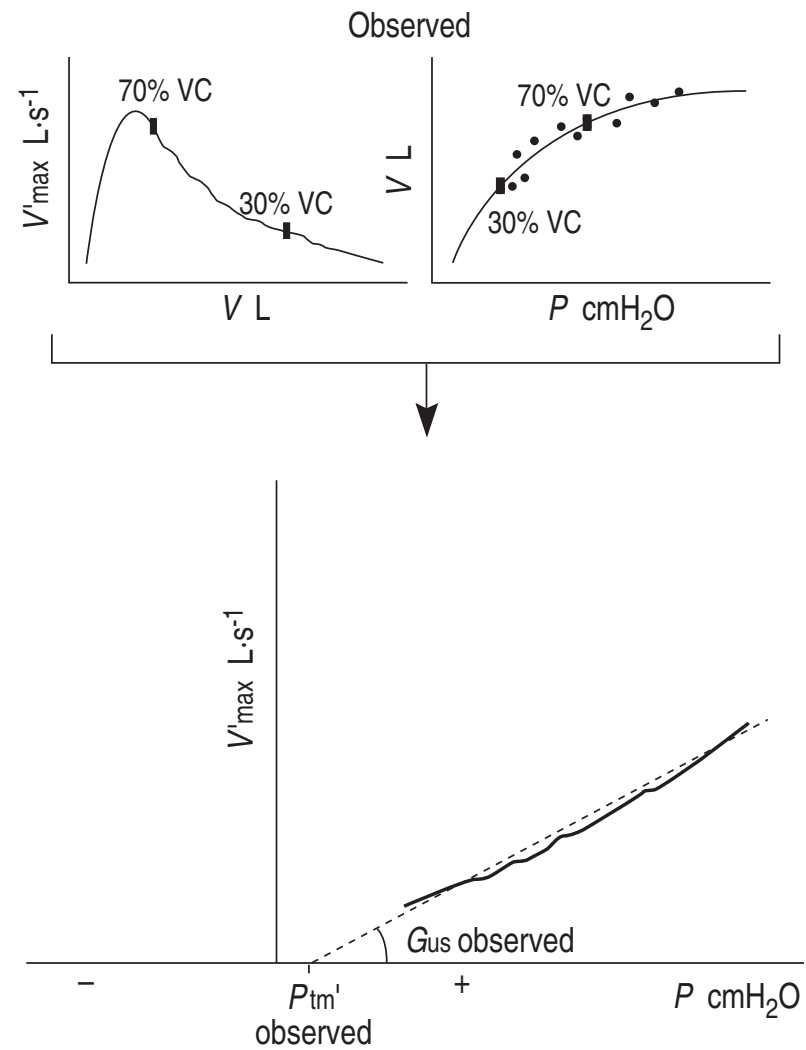

$$
\text { Gus } \%=\frac{\text { Gus observed }}{\text { Gus predicted }} \times 100 \%
$$

Fig. 1. - For each patient a maximal flow-static recoil (MFSR) plot is obtained by plotting maximal flow ( $V$ 'max) of the volume-flow curve against the static transpulmonary pressures at the same lung volumes. The slope of the linear part of the MFSR plot between 70 and $30 \%$ of vital capacity (VC) is an estimation of upstream airway conductance (Gus), and the pressure-axis intercept is an estimate of the airway collapsibility of the flow-limiting segments $(P \mathrm{tm})$. For each patient, a predicted MFSR curve is obtained by plotting predicted $V$ 'max at 75,50 and $25 \%$ of VC of the volume-flow curve against the predicted static transpulmonary pressures at the same lung volumes. The slope of the MFSR plot between 75 and $25 \%$ vital capacity is $G$ us(pred), and the pressure-axis intercept is $P_{\mathrm{tm}}$ '(pred). $G$ us $\%$ calculated in the figure and $\Delta P_{\mathrm{tm}}{ }^{\prime}\left(=P \mathrm{tm}^{\prime}(\mathrm{pred})-P_{\mathrm{tm}}{ }^{\prime}\right)$ are used for statistical analysis.

\section{Morphological studies}

Surgically resected specimens were inflated with either $10 \%$ formalin or $2.5 \%$ glutaraldehyde, at a pressure of $25 \mathrm{cmH}_{2} \mathrm{O}$, and submerged in fixative for at least $24 \mathrm{~h}$. The fixed specimens were then sliced serially at $1 \mathrm{~cm}$ intervals in a sagittal plane. Three to six intrapulmonary cartilaginous airways, which were cut in cross-section, were randomly selected from each specimen for morphometric analysis. Tissue blocks containing cartilaginous airways in cross-section were decalcified, embedded in paraffin, transversely cut at $5 \mu \mathrm{m}$ thickness and stained with haematoxylin and eosin, and with Masson's trichrome. Additionally, five lung tissue blocks were obtained in a stratified random fashion from a parasagittal slice for morphological grading of membranous and respiratory bronchioles and processed in the same way.

\section{Measurement of airway dimensions}

Sections from cartilaginous airways that did not show bifurcation or disruption of the wall were selected for measurement. Airway dimensions were measured on the haematoxylin and eosin stained sections using a microscope (Nikon) fitted with a camera lucida that superimposed the cursor-light of a digitizing board on the microscopic image of the airway (Bioquant; R\&M Biometrics Inc., Nashville, TN, USA).

Airways that were too large to be viewed entirely using a microscope were projected with a slide projector, their images were traced onto paper, and the tracings were measured on the digitizing board. The measurements that were made are shown in figure 2, and include: basement membrane perimeter $(\mathrm{Pbm})$; and the area of the lumen (and epithelium) contained within the light microscopic image of the basement membrane(Abm); the outer muscle perimeter (Pom), traced at the outer edge of the smooth muscle layer and the enclosed area (Aom); the outer perimeter $(\mathrm{Po})$, and the outer area (Ao) defined by the outer



Fig. 2. - Diagram of measured airway dimensions. 
edge of the adventitial tissue. From these measurements, total wall area (WAtot $=\mathrm{Ao}-\mathrm{Abm}$ ) and inner wall area $(\mathrm{WAi}=\mathrm{Aom}-\mathrm{Abm})$ were calculated. The total area of cartilage in the airway wall (WAcart) was calculated by tracing every piece of cartilage separately and calculating the sum of the areas.

To measure the area occupied by smooth muscle (WAm), an automated image analysis system (Bioview, Infrascan, Vancouver BC, Canada) was used. The smooth muscle was segmented from the airway wall in a trichrome stained section using operator defined colour threshholding. The area of the muscle was calculated automatically. The nomenclature used is according to the special communication concerning subdivisions of the bronchial wall [16]. All measurements of airway dimensions were performed by the same observer (HT). Perimeters (Pbm, Pom, $\mathrm{Po}$ ), were measured twice; if the difference between both measurements exceeded $10 \%$, they were repeated. Intraobserver variability was assessed by remeasurement of 10 randomly selected airways with an interval of 2 months. Interobserver variability was assessed by remeasurement of 10 randomly selected airways by a second observer.

\section{Measurement of bronchiolar inflammatory changes}

For each specimen, 5-10 membranous airways were graded for the severity of small airways disease using a modification of the pictorial grading method of Cosio and co-workers $[17,18]$. The following indices were graded: inflammation; fibrosis; muscle hypertrophy; pigment deposition; goblet cell metaplasia; and squamous cell metaplasia. For each airway, these six morphological indices were compared with pictorial reference standards with a score from 0 (normal) to 3 (most abnormal). Next, the mean score for each morphological index for each individual was calculated by summing the scores of the airways examined and dividing by the number of airways examined. The average score for that variable was expressed as a percentage of maximal possible score. A total membranous airways disease score for each specimen was then calculated by summing the mean scores of the six morphological indices (maximal score $6 \times 100=600)$.

\section{Statistical analysis}

Correlation coefficients given are Pearson's. The relationships between airflow obstruction (FEV1, FEV1/FVC), on the one hand, and various measures of lung recoil ( $P$ L,max, $P$ L,60, log k), upstream conductance ( $G$ us $\%$, sGus), airway collapsibility $\left(P \mathrm{tm}^{\prime}, \Delta P_{\mathrm{tm}}\right)$, and airway dimensions (WAi, WAtot, WAcart) on the other, were investigated using multiple linear regression analysis.

The intra- and interobserver variability of morphometric measurements were calculated by expressing the difference between the first and second measurement as a percentage of the average of both measurements. This percentage difference was plotted against the average $P$ bm to detect if there were systematic differences dependent on airway size.

Repeated measurement analysis of variance (RMANOVA), which allows for differences between and within patients, was used to assess the relationships between airway wall dimensions (WAtot, WAcart, WAm) and air- way size $(\mathrm{Pbm})$. To obtain linear regressions with approximately normal distributions, it was necessary to apply a square root transformation to the airway wall dimensions. In the analysis, the airway size values were centred by subtracting the mean value for $\mathrm{Pbm}$ of $14 \mathrm{~mm}$ from all values of $\mathrm{Pbm}$. The intercept of an individual regression line of a particular airway wall dimension as a function of $\mathrm{Pbm}$, therefore, denotes its level at a $\mathrm{Pbm}$ of $14 \mathrm{~mm}$. The intercept and slope of the regression lines were investigated for their linear relationship with FEV1 ( $\%$ pred), FEV1/FVC ( $\%$ pred), $\Delta P \mathrm{tm}^{\prime}$, and $G$ us $\%$ using an iterative search for optimal values. RMANOVA analyses the patients as a continuum and, thus, avoids the bias that results from dividing patients into subgroups $[19,20]$. The level of significance was set at a p-value equal to 0.05 (two-sided). Data are expressed as mean \pm SD and range, unless otherwise indicated.

\section{Results}

\section{Lung function}

The mean lung function values of the patients in this study are shown in table 2 . Forty nine patients had no significant airflow obstruction (FEV1/FVC $> \pm 2$ sD FEV1/ FVC(pred)) 12 patients had mild airflow obstruction (FEV1/FVC between -2 and -3 sD FEV1/FVC(pred)), and 11 patients had severe airflow obstruction (FEV1/FVC $<-3$ SD FEV1/FVC(pred)). Increased functional residual capacity (FRC $>$ FRC(pred) $+2 \mathrm{SD}$ ) was present in 21 out of 72 patients, and increased residual volume (RV $>\mathrm{RV}$ (pred)+2 SD) in 29 out of 72 patients. Loss of elastic recoil pressure $(\mathrm{k}>\mathrm{k}($ pred $)+2 \mathrm{SD})$ was present in 8 out of 72 patients.

\section{Table 2. - Lung function characteristics}

\begin{tabular}{lrrl}
\hline TLC \% pred & $\mathrm{n}=72$ & $109 \pm 15$ & $(81-154)$ \\
FRC \% pred & $\mathrm{n}=72$ & $123 \pm 24$ & $(70-177)$ \\
RV \% pred & $\mathrm{n}=72$ & $133 \pm 34$ & $(66-219)$ \\
FEV1 \% pred & $\mathrm{n}=72$ & $94 \pm 18$ & $(58-135)$ \\
FVC \% pred & $\mathrm{n}=72$ & $96 \pm 13$ & $(64-134)$ \\
FEV1/FVC \% pred & $\mathrm{n}=72$ & $92 \pm 12$ & $(55-114)$ \\
$P \mathrm{~L}, \max \%$ pred & $\mathrm{n}=72$ & $83 \pm 28$ & $(28-171)$ \\
$P \mathrm{~L}, 90 \%$ pred & $\mathrm{n}=72$ & $79 \pm 21$ & $(40-141)$ \\
$P \mathrm{~L}, 60 \%$ pred & $\mathrm{n}=72$ & $55 \pm 46$ & $(10-231)$ \\
$\mathrm{k} \%$ pred & $\mathrm{n}=72$ & $110 \pm 51$ & $(17-437)$ \\
$\mathrm{B} / \mathrm{A} \%$ pred & $\mathrm{n}=72$ & $81 \pm 20$ & $(40-157)$ \\
$G$ us\% male \% pred & $\mathrm{n}=44$ & $108 \pm 49$ & $(36-246)$ \\
$G$ us\% female \% pred & $\mathrm{n}=15$ & $143 \pm 73$ & $(67-283)$ \\
$\Delta P$ tm' male $\mathrm{cmH}_{2} \mathrm{O}$ & $\mathrm{n}=44$ & $0.15 \pm 1.9$ & $(-3.8-4.8)$ \\
$\Delta P$ tm' female $\mathrm{cmH}_{2} \mathrm{O}$ & $\mathrm{n}=15$ & $0.02 \pm 1.9$ & $(-2.5-5.3)$ \\
\hline$V$ alues ar &
\end{tabular}

Values are presented as mean $\pm \mathrm{SD}$, and range in parenthesis. TLC: total lung capacity; $\%$ pred: percentage of predicted value; FRC: functional residual capacity; RV: residual volume; FEV1: forced expiratory volume in one second; FVC: forced vital capacity; FEV1/FVC: forced expiratory volume in one second as fraction of forced vital capacity; $P \mathrm{~L}$,max: transpulmonary pressure at TLC: PL,90: transpulmonary pressure at $90 \%$ TLC: $P$ L,60: transpulmonary pressure at $60 \%$ TLC: $\mathrm{k}$ : exponential constant describing shape of the pressure-volume curve; B/A: ratio describing position of the pressure-volume curve in respect to the pressure axis; A: the lung volume at infinite transpleural pressure; $\mathrm{B}$ : the lung volume difference between $\mathrm{A}$ and the lung volume at a transpleural pressure of $0 \mathrm{cmH}_{2} \mathrm{O} ; \mathrm{Gus} \%$ : airway conductance upstream of the flow-limiting segment; $\Delta P_{\mathrm{tm}}$ ': critical transmural pressure at which the flow-limiting segments restrict flow calculated as $P$ tm' (pred) - $P$ tm'. 


\section{Maximal flow-static recoil curves}

The MFSR curves derived from the patients contained $62 \pm 21$ (SD) (range 17-125) data points in the 70-30\% $\mathrm{VC}$ volume interval and were linear within that interval in 59 patients $\left(\mathrm{R}^{2}=0.99 \pm 0.01\right.$; range $\left.0.95-0.99\right)$. For 13 patients, the relationship within the $70-30 \%$ VC volume interval was clearly not linear at the upper end. The flow-volume curves of these patients showed that the peak expiratory flow was not reached within the first $30 \%$ of the expired VC due to submaximal effort. A submaximal flow-volume manoeuvre is likely to influence both the slope and the intercept of the linear part of the MFSR curve, and these subjects were, therefore, excluded from further analysis.

Figure 3 shows the values for $G$ us(pred) and $P$ tm'(pred) as a function of age for male and female subjects of the

a)

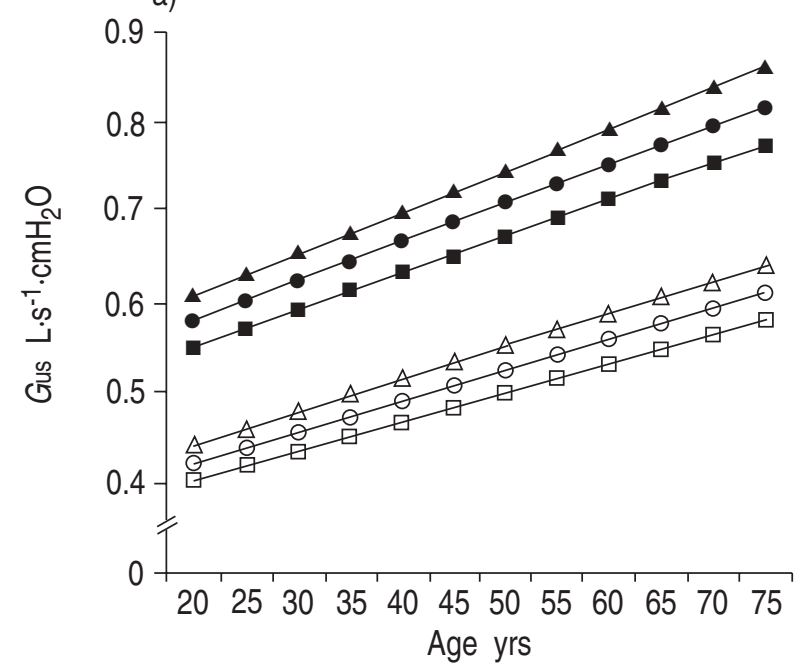

various heights. The relationship between the three predicted flow and pressure points at 75, 50 and 25\% VC was adequately described as a linear relationship for all patients $\left(\mathrm{R}^{2}=0.99\right.$; range $\left.0.96-0.99\right)$. Multiple regression analysis showed that $G$ us(pred) and $P$ tm'(pred) were significantly related to age and sex. $G$ us(pred) increased in males and females of $170 \mathrm{~cm}$ height for an increase in age of $10 \mathrm{yrs}$ by 0.04 and $0.03 \mathrm{~L} \cdot \mathrm{s}^{-1} \cdot \mathrm{cmH}_{2} \mathrm{O}^{-1}$, respectively $(\mathrm{p}<0.001)$. Gus(pred) was on average $0.15 \mathrm{~L} \cdot \mathrm{s}^{-1}$. $\mathrm{cmH}_{2} \mathrm{O}^{-1}$ higher in males than in females $(\mathrm{p}<0.001)$. $P$ tm'(pred) increased in males and females of $170 \mathrm{~cm}$ height for an increase in age of 10 yrs by 0.25 and 0.6 $\mathrm{cmH}_{2} \mathrm{O}$, respectively. $P \mathrm{tm}^{\prime}$ (pred) was higher in males than in females $(\mathrm{p}<0.001)$. This difference decreased with increasing age. Figure 4 shows the age dependence of the predicted MFSR curve both for male and female subjects.

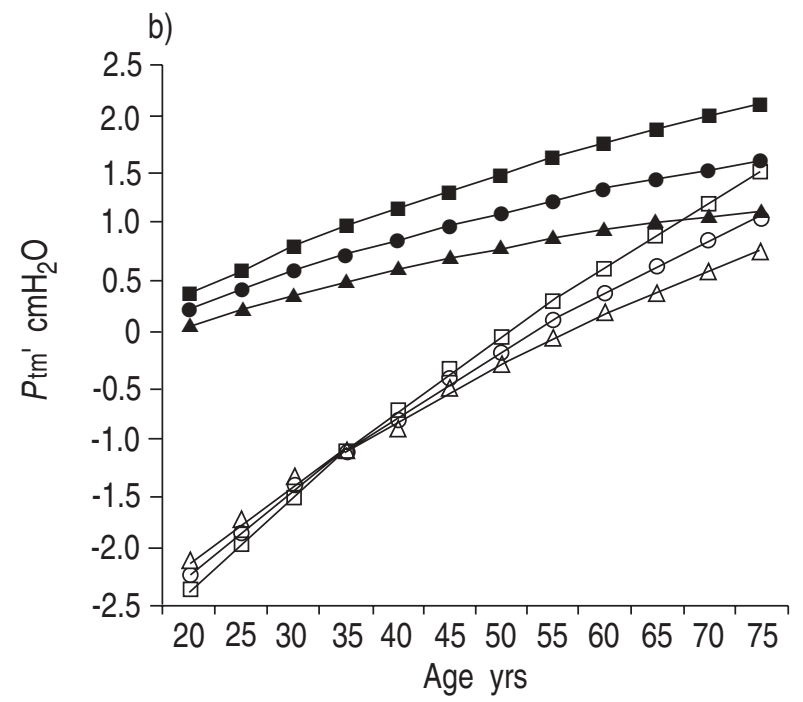

Fig. 3. - a) Predicted airway conductance versus age; and b) airway collapsibility versus age. Gus: airway conductance upstream of the flow-limiting segment; $P$ tm': critical transmural pressure causing airway collapse at the flow-limiting segment. Height: $\longrightarrow-$ : male $160 \mathrm{~cm} ; \longrightarrow \bullet-$ male $170 \mathrm{~cm} ; \multimap$ : male $180 \mathrm{~cm} ; \multimap-$ : female $160 \mathrm{~cm} ;-\mathrm{O}-$ : female $170 \mathrm{~cm} ;-\Delta-$ : female $180 \mathrm{~cm}$.


Fig. 4. - Change of the predicted maximal flow-static recoil (MFSR) plot with age for: a) males of $170 \mathrm{~cm}$ height; and b) females of $170 \mathrm{~cm}$ height. The predicted MFSR plot is the regression line through predicted maximal flow $\left(V^{\prime} \max \right)$ and predicted static transpulmonary pressures at 75, 50 and 25\% vital capacity. The slope of the MFSR plot becomes steeper and the pressure axis intercept higher with increasing age both for

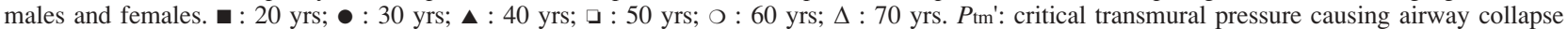
at the flow-limiting segment. 
a)

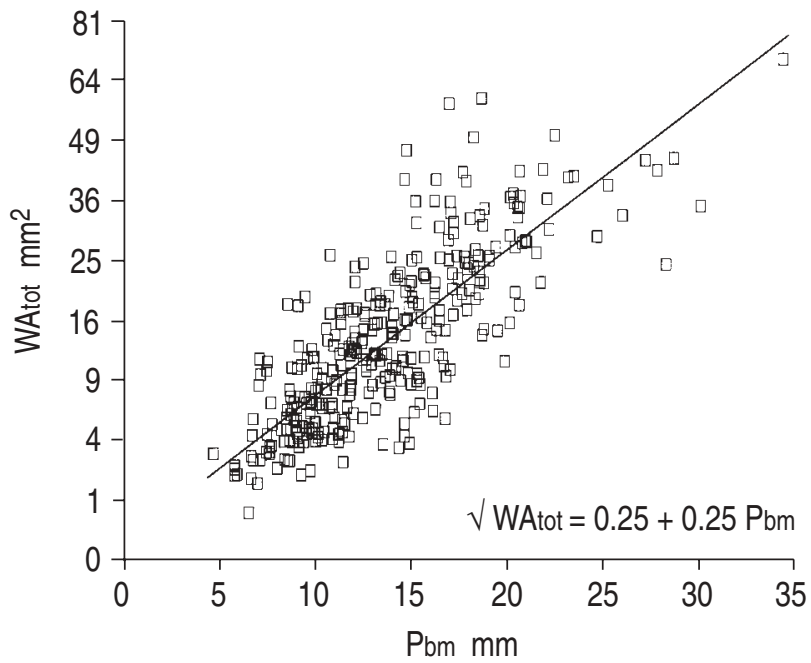

b)

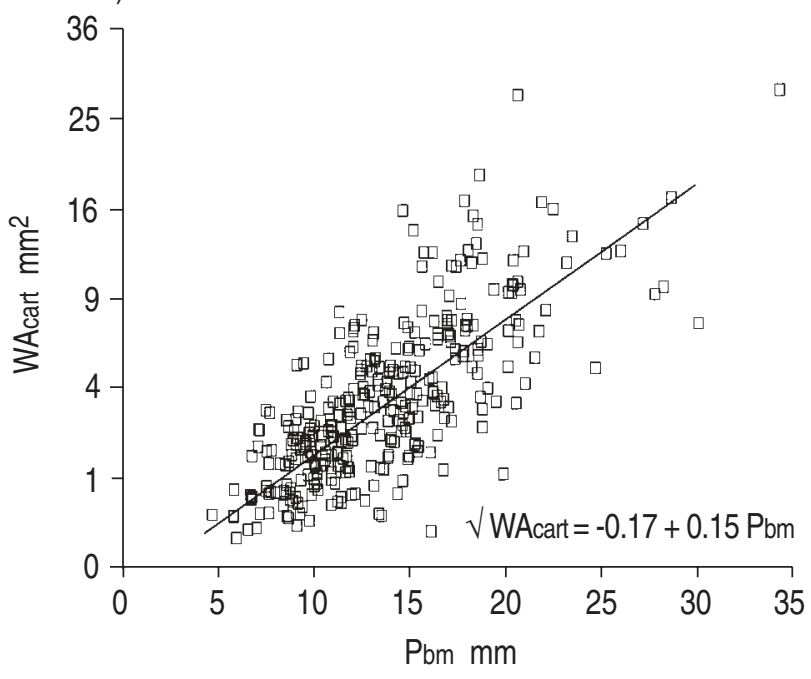

Fig. 5. - Morphometric airway dimensions versus airway size. There are 341 data points from 72 patients plotted in this figure. a) WAtot: total wall area; Pbm: perimeter of basement membrane. The regression lines represents the relationship between WAtot versus Pbm. b) WAcart: cartilage area. The regression lines represent the relationship between WAcart versus $\mathrm{Pbm}$.

\section{Morphological studies}

Morphometric measurements were made on 341 cartilaginous airways from 72 patients (mean 4.7, range 37 airways per patient). Mean airway size expressed as the $\mathrm{Pbm}$ was $13.8 \pm 4.7(5-33) \mathrm{mm}$. This corresponds to a mean airway diameter of $4.4 \pm 1.5(1.5-10.9) \mathrm{mm}$, or the fifth branch \pm 1 [21]. The mean intraobserver variability was $-8.3 \pm 7.5 \%$ for WAtot and $0.1 \pm 3.4 \%$ for WAcart. The mean interobserver variability was $-13.9 \pm 11.1 \%$ for WAtot and $2.6 \pm 3.7 \%$ for WAcart. The intra- and interobserver variability for $\mathrm{Pbm}$, $\mathrm{Pom}, \mathrm{Po}$, and WAm has been described previously [22]. There was no systematic relationship between airway size $(\mathrm{Pbm})$ and the intra- or interobserver difference for any variable. Highly significant $(p<0.001)$ linear relationships were found between airway size $(\mathrm{Pbm})$ and airway wall dimensions $(\sqrt{W A t o t}$, $\sqrt{W A}$ cart) (fig. 5). The linear relationships for $\mathrm{Pbm}$ and WAi and WAm have been described previously [22].

The mean membranous airways disease score (MADS) was 134 \pm 47 (14-297). Among the six parameters evaluated, fibrosis followed by inflammation scored highest.

\section{Structure function relationships}

Table 3 shows pairwise the correlation coefficients for measurements of airflow obstruction (FEV1 (\% pred) and $\mathrm{FEV} 1 / \mathrm{FVC}(\%$ pred)) and measurements of elastic recoil $(P \mathrm{~L}, \max (\%$ pred) and $P \mathrm{~L}, 60(\%$ pred $))$, upstream conductance $(G \mathrm{us} \%)$, airway collapsibility $(\Delta P \mathrm{tm})$, airway wall dimensions (WAi, WAcart), and airway inflammation. Airflow obstruction increased with lower $P$ L, max ( $\%$ pred), $P$ L,60 (\% pred), and $G$ us $\%$. In a previous study, we showed that airflow obstruction increased significantly with thickening of WAi but not with WAm [22]. In this study, we found no significant correlation of airflow obstruction and WAtot (data not shown) or WAcart. The predictive values of $P \mathrm{~L}$, max ( $\%$ pred), $P$ L,60 ( $\%$ pred), WAi, and WAcart for airflow obstruction were tested using multiple regression analysis. It was found that $P \mathrm{~L}, 60$ (\% pred) $(\mathrm{p}=0.006)$ and WAi $(\mathrm{p}=0.01)$ were both most predictive regarding $\mathrm{FEV}_{1}(\%$ pred $)\left(\mathrm{R}^{2}=0.22\right)$ and FEV1/FVC ( $\%$ pred) $\left(\mathrm{R}^{2}=0.24\right)$. $P$ L,max $(\%$ pred $)$ and WAcart did not add significantly to the predictive value for either FEV1 (\% pred) or FEV1/FVC (\% pred).

Table 3. - Correlation coefficients of structure-function relationships

\begin{tabular}{|c|c|c|c|c|c|c|c|c|}
\hline & $\mathrm{FEV}_{1}$ & $\mathrm{FEV}_{1 / \mathrm{FVC}}$ & Gus $\%$ & $\Delta P \mathrm{tm}^{\prime}$ & $P_{\mathrm{L}, \max }$ & $P \mathrm{~L}, 60$ & WAi & WAcart \\
\hline $\mathrm{FEV}_{1} \%$ pred & - & $0.67 * * *$ & $0.58 * * *$ & NS & $0.30 *$ & $0.35 * *$ & $-0.33 * *$ & NS \\
\hline FEV1/FVC $\%$ pred & $0.67 * * *$ & - & $0.47 * * *$ & NS & $0.55 * * *$ & $0.40 * *$ & $-0.32 *$ & NS \\
\hline Gus $\%$ & $0.58 * * *$ & $0.47 * * *$ & - & NS & NS & NS & $-0.25 \div$ & NS \\
\hline$\Delta P \mathrm{tm}^{\prime}$ & NS & NS & NS & - & NS & $-0.31 *$ & NS & NS \\
\hline$P \mathrm{~L}, \max \%$ pred & $0.30 *$ & $0.55 * * *$ & NS & NS & - & $0.30 *$ & NS & NS \\
\hline$P_{\mathrm{L}, 60} \%$ pred & $0.35 * *$ & $0.40 * *$ & NS & $-0.31 *$ & $0.30 *$ & - & NS & NS \\
\hline WAi & $-0.33 * *$ & $-0.32 *$ & $-0.25^{\ddagger}$ & NS & NS & NS & - & $0.31 *$ \\
\hline WAcart & NS & NS & NS & NS & NS & NS & $0.31 *$ & - \\
\hline MADS & $-0.30 *$ & $-0.28 *$ & $0.24 * *$ & NS & $-0.30 *$ & NS & $0.4 * *$ & NS \\
\hline
\end{tabular}

WAi: inner wall area; WAcart: area of cartilage; MADS: membranous airways disease score; NS: not significant. For further definitions see legend to table 2 . $*$ : $\mathrm{p}=0.06 ; *: \mathrm{p}<0.05 ; * *: \mathrm{p}<0.01 ; * * *: \mathrm{p}<0.001$. 
$G$ us $\%$ decreased as the inner wall area became thicker ( $r=-0.25 ; \mathrm{p}=0.03$, one-sided) or as the MADS increased ( $\mathrm{r}=-0.24 ; \mathrm{p}=0.04$, one-sided). Gus\% did not correlate with any of the other airway dimensions (WAtot, WAm, WAcart). In addition, the predictive value of WAi, WAtot, WAm, WAcart for Gus were tested using multiple regression analysis. WAi was most predictive regarding Gus\% (p=0.04), WAtot, WAm and WAcart did not add significantly to the predictive value regarding $G$ us $\%$. $\Delta P \mathrm{tm}^{\prime}$ as an estimate of airway collapsibility did not significantly correlate with airflow obstruction (FEV1 (\% pred), FEV1/FVC (\% pred)), airway dimensions (WAtot, WAi, WAcart, WAm), or to the MADS.

\section{Discussion}

In this study, we investigated whether airflow obstruction was related to lung elastic recoil pressure, airway conductance and collapsibility, and whether airway conductance and collapsibility were related to airway inflammation and airway wall dimensions. Airway conductance and collapsibility were calculated from MFSR plots. The results show a significant relationship between airflow obstruction and recoil, airflow obstruction and upstream resistance and between the inner wall area and upstream conductance. No significant correlation was found for the MFSR plot estimate of airway collapsibility and airflow obstruction or airway wall dimensions or inflammation. The amount of cartilage was not correlated to airway inflammation or to airflow obstruction.

Airflow obstruction in relation to lung elastic recoil, airway conductance, and airway collapsibility

One third of the patients studied suffered from mildto-severe airflow obstruction. Lung elastic recoil, airway conductance, and airway collapsibility are all important in the pathogenesis of airflow obstruction. Loss of lung elastic recoil pressure results in a reduction of the driving force to generate airflow, and is thought to decrease airway conductance secondary to a loss of the tethering forces that distend the airways $[1,2,23]$. Airflow obstruction correlated significantly with loss of lung elastic recoil pressure in the group of patients studied.

The peripheral airway conductance has been found to be decreased in COPD. This implies that frictional losses in these airways will be increased [24, 25]. During forced expiration, equal pressure points are formed where lateral pressure losses due to frictional and convective acceleration equal the lung elastic recoil pressure. Flowlimiting segments are formed downstream from these equal pressure points [25]. As a result of increased frictional losses and/or the loss of recoil pressure, the equal pressure point will move upstream, to peripheral airways that are more collapsible than central airways. Therefore, a smaller pressure difference over the airway wall is required to collapse the airway. In the group of patients studied, a strong correlation was found between the airway conductance upstream of the flow-limiting segment $(G \mathrm{us} \%)$ and airflow obstruction (FEV1, FEV1/FVC).

Airway collapsibility of the flow-limiting segment is thought to be an important determinant of airflow obstruction. In the present study, no significant correlation was found between the collapsibility of the flow-limiting segment as derived from the MFSR plot $\left(\Delta P \mathrm{tm}^{\prime}\right)$ and airflow obstruction. This could mean that collapsibility might not be an important factor, or that the $\Delta P \mathrm{tm}^{\prime}$ does not adequately represent the collapsibility of the flowlimiting segment. We think the latter is true for reasons stated below.

\section{Airway conductance and collapsibility versus structure and inflammatory changes}

Reduced airway conductance can result from inflammatory thickening of the airway wall, contraction of airway smooth muscle, loss of tethering forces by the parenchyma which surrounds the airways, and the presence of secretions within the lumen. Cosio et al. [17] showed that inflammation of the airways was related to airflow obstruction; although this was not confirmed in a more recent study in a large group of patients [2]. Inflammation has been found to be related to the thickness of the airway wall both in cartilaginous and noncartilaginous airways of patients with COPD [22, 26, 27]. In addition, we and others have previously shown that the thickness of the inner wall area is related to airflow obstruction (FEV1/FVC\%) $[22,26]$. In the present study, a significant correlation was found between the thickness of the inner airway wall area and Gus\%. No significant relationship was found between $G$ us $\%$ and total airway wall thickness, which is likely to be explained by the more variable measurement of the latter.

During forced expiration, the airways will be compressed at and downstream from the flow-limiting segments and, therefore, maximal airflow is limited [25]. Airway wall structure and diameter are important determinants of the compressibility of the airway at the site of the flow-limiting segments. It is thought that the $P \mathrm{tm}^{\prime}$ as calculated from the MFSR model reflects the compressibility of the airways at the flow-limiting segment. The present study provides a number of observations that argue against the validity of $P \mathrm{tm}^{\prime}$ as a measure of the collapsibility of the flow-limiting segments. Firstly, airway cartilage is considered to be an important structure that resists dynamic compression [28]. We therefore expected a significant correlation between the amount of cartilage and $P \mathrm{tm}^{\prime}$. In the present study, no such correlation could be demonstrated. Since the mechanical properties of airway cartilage were not investigated, it cannot exclude that these properties would relate to airway collapsibility. In fact, Moreno et al. [29] showed that the proteolytic enzyme, papain, could weaken airway cartilage, while its histological appearance remained unchanged.

Secondly, it is likely that chronic inflammation affects the collapsibility of the airways at the flow-limiting segment. However, in the present study, no such significant correlation could be detected between airway inflammation parameters and $\Delta P \mathrm{tm}^{\prime}$. Thirdly, increased thickness of the airway wall would be expected to decrease airway collapsibility [30]. Again, no correlation was found between total airway wall thickness, or inner wall thickness and $\Delta P \mathrm{tm}^{\prime}$. 
Fourthly, airflow obstruction itself did not correlate to $\Delta P \mathrm{tm}^{\prime}$. Finally, we did not find an increase of $P \mathrm{tm}^{\prime}$ with age, as was predicted by our reference values. The increase in $P$ tm'(pred) is in agreement with the study by YeRnAult et al. [31], who found an increase of $P \mathrm{tm}^{\prime}$ versus age in a group of 74 healthy subjects. But, as was stated by these authors, a number of studies showed that airway compliance decreases with age $[32,33]$. The increase of $P$ tm' with age could be explained by a more peripheral position of the flow-limiting segment, since peripheral airways are known to be more compliant than central airways [34].

We did not study whether smooth muscle tone or parenchymal tethering forces were correlated to $\Delta P \mathrm{tm}$ '. Constriction of smooth muscle is known to decrease airway collapsibility $[28,35]$. The importance of the lung parenchyma for airway collapsibility is still a matter of debate. The alveolar walls attach to the outside of the airway and probably provide an elastic load to airway smooth muscle when it shortens or when the airway is compressed [36]. LAMB et al. [37] found that loss of these alveolar attachments was associated with airflow obstruction; this was not found by others [2]. Since we found no significant correlations between airway dimensions, inflammation, or airflow obstruction and $\Delta P \mathrm{tm}^{\prime}$, we think it unlikely that $P_{\mathrm{tm}}$ ' is a valid estimate of the collapsibility of the flow-limiting segment. Calculation of $P \mathrm{tm}^{\prime}$ is determined by extrapolation of the MFSR curve to zero flow. This extrapolation assumes a linear behaviour of the maximal flow versus static recoil relationship below 30\% FVC. If the pressure-flow relationship deviates from a linear relationship below $30 \%$ FVC, the actual and predicted zero flow intercept could be very different.

\section{Airway cartilage, inflammation and airflow obstruction}

Previous studies have suggested that chronic inflammation reduces cartilage volume and, therefore, contributes to increased airflow obstruction [3, 6, 38, 39]. This was not confirmed in other studies $[7,8]$. In the present study, we could not demonstrate a correlation between inflammatory changes in the airways and the amount of airway cartilage, nor a correlation between the amount of cartilage and the severity of airflow obstruction. The older studies that investigated the relationship between inflammation and airway cartilage were handicapped by the fact that the appropriate method to correct for airway size was not yet known [40]. A recent study by NAGAI et al. [6] expressed cartilage as a volume proportion of the total wall area. Inflammation of the airways results in an increased thickness of the airway wall and, therefore, could result in a reduced volume proportion of airway cartilage [22]. Since we investigated a large number of patients and corrected for airway size, we think that the volume of cartilage is not reduced by inflammation and is not related to airflow obstruction.

\section{Predicted values of airway conductance and airway col- lapsibility}

To our knowledge, no reference values are available for $G$ us and $P$ tm'. In previous studies, Gus was corrected for lung volume by dividing $G$ us by the predicted or actual TLC of the subject (table 4) [9, 41]. In these studies, patients were compared to a limited number of healthy subjects, without matching for age or sex. Yernault et al. [31] described an increase in $G$ us with age that was comparable for males and females. Gus was higher in males than in females. We calculated predicted values for $G$ us and $P \mathrm{tm}^{\prime}$ (Gus(pred) and $P$ tm'(pred)) for each patient using reference values both for elastic recoil pressure and maximal expiratory flows $[11,14]$. In agreement with the study of Yernault et al. [31], Gus(pred) and $P \mathrm{tm}^{\prime}$ (pred) increased with age and were higher for males than for females. An increase in Gus with age has been described by a number of authors [31, 42-44]. The decrease of maximal flows at fixed lung volumes, with increasing age, is predominantly related to decreased lung elastic recoil pressure. Our results suggest that the decrease in recoil is greater than the decrease in flow. We speculate that this preservation of flow could be the result of a disproportionately greater loss of elasticity in the airways relative to the loss of recoil in the parenchyma. This could cause airways to be more distended at any lung elastic recoil pressure.

Our predicted values for $G$ us and $P$ tm' were derived from two prediction equations generated in different groups

Table 4. - Maximal flow-static recoil estimates of airway conductance and collapsibility

\begin{tabular}{|c|c|c|c|c|c|}
\hline $\begin{array}{l}\text { First } \\
\text { author }\end{array}$ & [Ref] & & $\mathrm{n}$ & $\begin{array}{c}P_{\mathrm{tm}^{\prime}} \\
\mathrm{cmH}_{2} \mathrm{O}\end{array}$ & $\begin{array}{c}\mathrm{s} G \text { us } \\
\mathrm{cmH}_{2} \mathrm{O}^{-1} \mathrm{~s}^{-1}\end{array}$ \\
\hline $\begin{array}{l}\text { LEAVER } \\
\text { ZAMEL } \\
\text { Tiddens }\end{array}$ & $\begin{array}{r}{[9]} \\
{[41]}\end{array}$ & $\begin{array}{l}\text { Controls } \\
\text { Controls } \\
\text { Predicted, all } \\
\text { Predicted, male } \\
\text { Predicted, female }\end{array}$ & $\begin{array}{r}10 \\
6 \\
59 \\
44 \\
15\end{array}$ & $\begin{array}{cl}-0.8 & (-3.8-1.7) \\
- & (0.5-0.9) \\
1.05 & (-0.95-2.5) \\
1.24 & (0.13-2.54) \\
0.51 & (-0.95-1.97)\end{array}$ & $\begin{array}{lr}0.09 & (0.06-0.12) \\
- & (0.08-0.14) \\
0.11 & (0.08-0.15) \\
0.12 & (0.10-0.15) \\
-\quad & (0.08-0.14)\end{array}$ \\
\hline $\begin{array}{l}\text { LEAVER } \\
\text { ZAMEL } \\
\text { ZAMEL } \\
\text { Tiddens }\end{array}$ & $\begin{array}{r}{[9]} \\
{[41]} \\
{[41]}\end{array}$ & $\begin{array}{l}\text { Patients } \\
\text { Emphysema } \\
\text { Peripheral obstr. } \\
\text { Patients, all } \\
\text { Male } \\
\text { Female }\end{array}$ & $\begin{array}{r}17 \\
5 \\
2 \\
59 \\
44 \\
15\end{array}$ & $\begin{array}{ll}3.1 & (0.6-5.8) \\
- & (1.1-2.7) \\
- & (1.5-3.3) \\
0.12 & (-3.8-5.3) \\
0.15 & (-3.8-4.8) \\
0.02 & (-2.5-5.3)\end{array}$ & $\begin{array}{lr}0.05 & (0.02-0.08) \\
-\quad & (0.08-0.19) \\
- & (0.05-0.09) \\
0.13 & (0.03-0.29) \\
0.12 & (0.03-0.29) \\
0.14 & (0.07-0.26)\end{array}$ \\
\hline
\end{tabular}

sGus: specific conductance upstream of the flow-limiting segment calculated as Gus divided by TLC of patient;

$P$ tm': collapsibility of flow-limiting segment; Peripheral obstr.: patients with obstruction of peripheral airways. 
of normal subjects. It can be argued that the increase in predicted $G$ us is an artifact caused by combining the two sources of data. However, we do not believe that this is the case. The mean value for $G$ us, for the nine normal male subjects of LEAVER et al. [9] (mean Gus=0.65 L.s $\mathrm{s}^{-1} \cdot \mathrm{cmH}_{2} \mathrm{O}^{-1}$; mean age $=35 \mathrm{yrs}$ ) fall within the predicted normal range (fig. 3). In addition, in this study we calculated the mean Gus for the 23 male subjects (mean age $63 \mathrm{yrs}$; height $174 \mathrm{~cm}$ ) without airflow obstruction (FEV1/VC (pred) $>-2 \mathrm{SD}$ ) and for the 21 male subjects (mean age $62 \mathrm{yrs}$; height $173 \mathrm{~cm}$ ) with airflow obstruction (FEV1/VC(pred) $<-2$ SD). For patients without airflow obstruction, $G$ us was $1.04 \mathrm{~L} \cdot \mathrm{s}^{-1} \cdot \mathrm{cmH}_{2} \mathrm{O}^{-1}(134 \%$ pred $)$, for patients with airflow obstruction $G$ us was $0.63 \mathrm{~L} \cdot \mathrm{s}^{-1} \cdot \mathrm{cmH}_{2} \mathrm{O}^{-1}$ (80\% pred). The increased $G$ us in the patients without airflow obstruction could be explained by the same process that we have invoked from the age-related increases; a greater loss of airway elasticity than lung elasticity. The decreased $G$ us in the patients with airflow obstruction is likely to be caused by inflammatory thickening of the inner wall area.

In conclusion, in a group of 59 chronic obstructive pulmonary disease patients, strong correlations were found between airflow obstruction on the one hand and lung elastic recoil and airway conductance on the other. No correlation was found between airflow obstruction and measures of airway collapsibility. Airway conductance was correlated to the inner wall thickness. No correlation was found between airflow obstruction and the volume of airway cartilage. Nor was there a significant correlation between the volume of the cartilage and airway inflammation. Therefore, changes in the amount of cartilage are probably not important for the pathogenesis of chronic obstructive lung disease. Finally, none of the airway dimensions was related to the maximal flow-static recoil plot estimate of airway collapsibility. Therefore, we think that the maximal flow static recoil model does not adequately estimate the collapsibility of the flow-limiting segment.

Acknowledgements: The authors would like to thank H.J.L. Brackel for advice on the manuscript, Ph.H. Quanjer for advice on the MFSR analysis, I. Beckers for preparing the manuscript, and J. van Dijk for preparing the graphics.

\section{References}

1. Zapletal A, Desmond KJ, Demizio D, Coates AL. Lung recoil and the determination of airflow limitation in cystic fibrosis and asthma. Pediatr Pulmonol 1993; 15: 13-18.

2. Hogg JC, Wright JL, Wiggs BR, Coxson HO, Opazo Saez A. Lung structure and function in cigarette smokers. Thorax 1994; 49: 473-478.

3. Tandon MK, Cambell AH. Bronchial cartilage in chronic bronchitis. Thorax 1969; 24; 607-612.

4. Thurlbeck W, Dunhill M, Hartung W. A comparison of three methods of measuring emphysema. Hum Pathol 1972; 1: 215-226.

5. Nagai A, West WW, Paul JL, Thurlbeck WM. The National Institutes of Health Intermittent Positive Pressure Breathing Trial: pathology studies. Am Rev Respir Dis 1995; 132: 937-945.

6. Nagai A, Thurlbeck WM, Konno K. Responsiveness and variability of airflow obstruction in chronic obstructive pulmonary disease. Am J Respir Crit Care Med 1995; 151: 635-639.

7. Dunhill MS, Massarella GR, Anderson JA. A comparison of the quantitative anatomy of the bronchi in normal subjects, in status asthmaticus, in chronic bronchitis, and in emphysema. Thorax 1969; 24; 176-179.

8. Mullen JB, Wright JL, Wiggs BR, Paré PD, Hogg JC. Reassessment of inflammation of airways in chronic bronchitis. BMJ (Clin Res Ed) 1985; 291(6504): 1235-1239.

9. Leaver DG, Tattersfield AE, Pride NB. Contributions of loss of lung recoil and of enhanced airways collapsibility to the airflow obstruction of chronic bronchitis and emphysema. J Clin Invest 1973; 52: 2117-2128.

10. American Thoracic Society. Standards for the diagnosis and care of patients with chronic obstructive pulmonary disease (COPD) and asthma. Am Rev Respir Dis 1987; 136: 225-243.

11. Quanjer PH, Dalhuijsen A, Zomeren BC. Summary equations of reference values. Bull Eur Physiopathol Respir 1983; 19 (Suppl. 5): 45-51.

12. Mead J, Whittenberger JL. Physical properties of human lungs measured during spontaneous respiration. $J$ Appl Physiol 1953; 5: 779-796.

13. Glaister DH, Schroter RC, Sudlow MF, Milic-Emili J. Bulk elastic properties of excised lungs and the effect of a transpulmonary pressure gradient. Respir Physiol 1972; 17: 347-364.

14. Colebatch HJH, Greaves IA, Ng CKY. Exponential analysis of elastic recoil and aging in healthy males and females. J Appl Physiol:Respirat Environ Exercise Physiol 1979; 47(7): 683-691.

15. Pride NB, Permutt S, Riley RL, Bromberger-Barnea B. Determinants of maximal expiratory flow from the lungs. J Appl Physiol 1967; 23: 646-662.

16. Bai A, Eidelman DH, Hogg JC, et al. Proposed nomenclature for quantifying subdivisions of the bronchial wall. J Appl Physiol 1994; 77(2): 1011-1014.

17. Cosio M, Ghezzo H, Hogg JC, et al. The relations between structural changes in small airways and pulmonary-function tests. $N$ Engl J Med 1977; 298: 1277-1281.

18. Wright JL, Cosio M, Wiggs B, Hogg JC. A morphologic grading scheme for membranous and respiratory bronchioles. Arch Pathol Lab Med 1985; 109(2): 163-165.

19. Feldman HA. Families of lines: random effects in linear regression analysis. J Appl Physiol 1988; 64(4): 1721-1732.

20. Schluchter MD. Module 5V. In: Dixon WJ, ed. BMDP Statistical Software Manual. Berkely, University of California Press, 1990; pp. 1207-1244.

21. Hammersley JR, Olson DE. Physical models of the smaller pulmonary airways. J Appl Physiol 1992; 72(6): 2402- 2414.

22. Tiddens HAWM, Paré PD, Hogg JC, et al. Cartilaginous airway dimensions and airflow obstruction in human lungs. Am J Respir Crit Care Med 1995; 152: 260266.

23. Fraser RG. Measurements of the calibre of human bronchi in three phases of respiration by cinebronchography. J Can Assoc Radiol 1961; 12: 102-112.

24. Yanai M, Sekizawa K, Ohrui T, Sasaki H, Takishima T. Site of airway obstruction in pulmonary disease: direct measurement of intrabronchial pressure. J Appl Physiol 1992; 72(3): 1016-1023.

25. Pedersen OF, Thiessen B, Lyager S. Airway compliance and flow limitation during forced expiration in dogs. $J$ Appl Physiol:Respirat Environ Exercise Physiol 1982; 52: $357-369$. 
26. Bosken CH, Wiggs BR, Paré PD, Hogg JC. Small airway dimensions in smokers with obstruction to airflow. Am Rev Respir Dis 142(3): 563-570.

27. Kuwano K, Bosken CH, Paré PD, et al. Small airways dimensions in asthma and chronic obstructive pulmonary disease. Am Rev Respir Dis 1993; 148: 1220-1225.

28. Olsen CR, Stevens AE, Pride NB, Staub NC. Structural basis for decreased compressibility of constricted trachea and bronchi. J Appl Physiol 1967; 23(1): 35-39.

29. Moreno RH, McCormack GS, Brendan J, et al. Effect of intravenous papain on tracheal pressure-volume curves in rabbits. J Appl Physiol 1986; 60(1): 247-252.

30. Lambert RK, Codd SL, Alley MR, Pack RJ. Physical determinants of bronchial mucosal folding. J Appl Physiol 1994; 77(3): 1206-1216.

31. Yernault J-C, de Troyer A, Rodenstein D. Sex and age differences in intrathoracic airways mechanics in norma man. J Appl Physiol: Respirat Environ Exercise Physiol 1979; 46: 556-564.

32. Croteau JR, Cook CD. Volume-pressure and length-tension measurements in human tracheal and bronchial segments. J Appl Physiol 1960; 16: 170-172.

33. Wilson AG, Massarella GR, Pride NP. Elastic properties of airways in human lungs postmortem. Am Rev Respir Dis 1974; 110; 716-729.

34. Tisi GM, Minh VD, Friedman PJ. In vivo dimensional respose of airways of different size to transpulmonary pressure. J Appl Physiol 1975; 39(1): 23-29.

35. Okazawa M, Paré PD. Pressure-area relationship of mem- branous airways in rabbit. Am J Respir Crit Care Med 1994; 149(4): A770.

36. Paré PD, Bai TR. The consequences of chronic allergic inflammation. Thorax 1995; 50: 328-332.

37. Lamb D, McLean A, Gillooly M, et al. Relation between distal airspace size, bronchiolar attachments, and lung function. Thorax 1993; 48; 1012-1017.

38. Maisel JC, Silvers GW, Mitchell RS, Petty TL. Bronchial atrophy and dynamic expiratory collapse. Am Rev Respir Dis 1968; 98: 988-997.

39. Thurlbeck WM, Pun R, Toth J, Frazer RG. Bronchial cartilage in chronic obstructive lung disease. Am Rev Respir Dis 1974; 109: 73-80.

40. James AL, Hogg JC, Dunn LA, Paré PD. The use of the internal perimeter to compare airway size and to calculate smooth muscle shortening. Am Rev Respir Dis 1988; 138(1): 136-139.

41. Zamel J, Hogg J, Gelb A. Mechanisms of maximal expiratory flow limitation in clinically unsuspected emphysema and obstruction of the peripheral airways. Am Rev Respir Dis 1975; 113: 337-345.

42. Gelb AF, Zamel N. Effect of aging on lung mechanics in healthy nonsmokers. Chest 1975; 68: 539-541.

43. Mead J, Turner JM, Macklem PT, Little JB. Significance of the relationship between lung recoil and maximum expiratory flow. J Appl Physiol 1967; 22(1): 95-108.

44. Gibson GJ, Pride NB, O'Cain C, Quagliato R. Sex and age differences in pulmonary mechanics in normal nonsmoking subjects. J Appl Physiol 1976; 41: 20-25. 